INSTITUT NATIONAL DE LA STATISTIQUE ET DES ETUDES ECONOMIQUES

Série des Documents de Travail du CREST

(Centre de Recherche en Economie et Statistique)

\author{
$n^{\circ}$ 2003-11 \\ Regulating a Polluting \\ Oligopoly : Emission Tax or \\ Voluntary Agreement?
}

M. DAVID1

Les documents de travail ne reflètent pas la position de l'INSEE et n'engagent que leurs auteurs.

Working papers do not reflect the position of INSEE but only the views of the authors.

1 CREST-LEI, 28 rue des Saints-Pères, 75007 Paris et Laboratoire d'Econométrie de l'Ecole Polytechnique de Paris. Email : david@ensae.fr 


\title{
Regulating a Polluting Oligopoly: Emission Tax or Voluntary Agreement?
}

\author{
Maia David*
}

February 2003

\begin{abstract}
This paper compares, in a polluting oligopoly, an emission tax and a new form of environmental policy that needs formal assessment: voluntary agreements (VA). There are here two ways of reducing pollution: output contraction and end-of-pipe abatement. Given the imperfect competition, firms' reaction to the tax is sub-optimal. They reduce output excessively in order to raise the price and do not abate enough. The VA is a take-it-or-leave-it contract on abatement effort, offered to the firms with the threat of a tax. It has a limited effect on output and always allows higher abatement than the tax. We find that the VA may be more efficient than the tax in a concentrated industry, when pollution is not too harmful and when the abatement technology is rather efficient and cheap.
\end{abstract}

Keywords: environmental policy choice, market power, voluntary agreements.

JEL classifications: H23, L13, L51, Q48

\section{Introduction}

Over the last decades, environmental regulation has mostly taken the form of regulatory standards. Experience, however, has demonstrated the limits of this kind of regulation. Incentive instruments such as taxes, subsidies

*CREST-LEI, 28 rue des Saints-Pères, 75007 Paris and Laboratoire d'Econométrie de l'Ecole Polytechnique de Paris. Tel: 01445827 58. E-mail: david@ensae.fr. I wish to thank Olivier Godard, Bernard Sinclair-Desgagné, Anne Perrot, Laurent Linnemer, Romain Lesur and Tarik Tazdaït, discutant at the 2002 AFSE Congress in Paris, for helpful comments. 
and tradable pollution permits have then increasingly drawn economists' attention. In particular, these instruments often solve informational problems encountered by regulatory standards ${ }^{1}$. Nevertheless, excluding informational issues, other factors matter in the comparison of environmental instruments. More precisely, the application of the environmental policy is modified when the regulator faces multiple distorsions and has an incomplete set of instruments to correct them.

Several examples illustrate this multi-distorsions context. For instance, when regulation is not harmonized among countries in an open economy, the environmental policy may deteriorate national firms' competitiveness compared to their foreign competitors. The regulator then has to take into account this negative impact of her intervention in order to avoid firms' closing or relocation. Quite a large literature focuses on this topic. This paper investigates a less studied case in which the environmental regulation creates undesirable distorsions due to imperfect competition among the polluting firms ${ }^{2}$. Note that this framework is relevant since many factories that emit massive pollution are owned by firms in concentrated industries such as steel, paper and chemicals.

In a polluting industry with imperfect competition, two sources of distorsion occur. One is due to pollution, and the other is the underproduction associated with the exercise of monopoly or oligopoly power. Environmental regulation reduces the generation of pollution but, by causing firms to reduce their output, it also amplifies the second source of distorsion. The optimality of the environmental policy is thus modified compared to the competitive framework.

For instance, as shown by Buchanan (1969) and Barnett(1980), a Pigovian tax, fixed at marginal damage of pollution, is not optimal anymore. Along the same lines, Conrad and Wang (1993) show that, in certain cases, a tax applied to an oligopoly has the same negative effect as a collusion among firms by implying an excessive price rise. In this paper, we assume firms may reduce pollution through an end-of-pipe abatement technology (i.e. a filter). We show that, given the imperfect competition, an emission tax does not lead to the optimal level of investment in the abatement technology. In reaction to the tax, firms act strategically by reducing output excessively in order to raise the price and do not abate enough.

Given the limits of some traditional environmental policies, a new form of regulation, called voluntary agreements (VAs), has widely developed since

\footnotetext{
${ }^{1}$ See a review of this literature in Cropper and Oates (1992).

${ }^{2}$ We assume the regulator cannot restore perfect competition.
} 
the 1990 's ${ }^{3}$. VAs are commitments from polluting firms in improving their environmental performances. They are generally implemented in combination with other instruments such as a tax or a standard that represent a threat to the firms if the VA fails. Despite their increasing implementation, VAs have received little critical discussions among academics and lack formal assessment. According to Brau and Carraro (1999), the use of VAs can be justified when other instruments induce undesirable distorsionary effects. In which way can VAs solve some of the problems faced by the emission tax within imperfect competition?

Real world inspection reveals the existence of VAs that allow firms to be exempted from an environmental tax if they invest in the adoption of a clean technology. It is the case of a VA introduced in Denmark in 1996 in combination with an existing tax on $\mathrm{CO}^{4}$. Compared to a tax, this form of VA stimulates the adoption of clean technologies, which reduces pollution for a given level of output, that is without amplifying the distorsion due to imperfect competition. The VA may therefore have an advantage over the tax in regulating a concentrated industry.

This paper compares, in a Cournot oligopoly, an emission tax and a VA modeled as a take-it-or-leave-it contract offered to the firms with the threat of a $\operatorname{tax}^{5}$. The offered contract is based on abatement effort, i.e. on a level of investment in an end-of-pipe abatement technology. An abatement technology is a specific form of clean technology ${ }^{6}$. It is however common as $52.3 \%$ of the investments in favor of the environment undertaken by polluting firms concern pollution treatment through an abatement technology ${ }^{7}$. Moreover, some industries, such as the steel industry, have very few possibilities to modify their production process to make it cleaner. Pollution treatment is then the only way to reduce pollution. We shall discuss how the model may be generalized to other forms of clean technologies.

Section 2 of this paper presents the basic assumptions of the model, firstbest equilibrium and the equilibrium before any environmental policy. Sections 3 and 4 respectively study the emission tax and the voluntary agreement. Section 5 then carries out a comparison of these two policies. The two final sections present a discussion of the model and our conclusions.

\footnotetext{
${ }^{3}$ See the OECD Report (1999) for a presentation of VAs.

${ }^{4}$ See Johannsen and Togeby (1998) for a presentation of the Danish VA.

${ }^{5}$ This form of VA is common in Europe.

${ }^{6}$ The adoption of clean technologies may imply a change in the production process, which is not the case with an abatement technology.

${ }^{7}$ http://www.belspo.be/belspo/ostc/geninfo/publ/pub_ostc/HL/rHL20w3_fr.pdf
} 


\section{Basic Assumptions, First-Best and Ex ante Equilibrium}

Throughout this paper we consider a partial equilibrium model with one consumption good and one pollutant generated by production. The consumption good is produced by $n$ identical firms engaged in Cournot competition.

As in Barnett(1980) and Katsoulacos and Xepapadeas (1995), pollution emissions can be abated through pollution treatment, using a filter or another abatement technology. Pollution emissions generated by firm $i$ are then $e\left(x_{i}, w_{i}\right)$ where $x_{i}$ denotes the firm's output and $w_{i}$ its abatement effort, i.e. a level of investment in the abatement technology. This function is additively separable and can be written as $e(x, w)=e_{1}(x)+e_{2}(w)$. Indeed, it is straightforward that end-of-pipe abatement does not modify the quantity of emissions generated by each unit of production. The derivatives of the emission function are: $e_{1}^{\prime}(x)>0$ (production generates pollution), $e_{2}^{\prime}(w)<0$ (abatement effort reduces pollution), $e_{1}^{\prime \prime}(x) \geq 0$ and $e_{2}^{\prime \prime}(w) \geq 0$.

Each firm $i$ 's cost function is written as $C\left(x_{i}, w_{i}\right)$. This cost function is also assumed to be additively separable in effort $w$ and output ${ }^{8}$, and can be written as : $C(x, w)=C_{1}(x)+C_{2}(w)$. The derivatives of the cost function are as follows: $C_{1}^{\prime}(x)>0, C_{2}^{\prime}(w)>0, C_{1}^{\prime \prime}(x) \geq 0$ and $C_{2}^{\prime \prime}(w) \geq 0$, that is production and abatement effort exhibit decreasing returns to scale.

Society's preferences are represented by an inverse demand function $P(X)$ and by a social damage function $V(E)$. Inverse demand $P(X)$ is downward slopping and is a function of aggregate output $X=\sum_{i} x_{i}$. The social damage function depends on aggregate emissions $E=\sum_{i} e\left(x_{i}, w_{i}\right)$ and is increasing and linear, $V^{\prime}=v, V^{\prime \prime}=0$.

The regulator is benevolent and maximizes social welfare $W$, measured as the sum of consumers' and producers' surplus minus external damage:

$$
W=\int_{0}^{X} P(u) d u-\sum_{i} C\left(x_{i}, w_{i}\right)-v \sum_{i} e\left(x_{i}, w_{i}\right)
$$

\footnotetext{
${ }^{8}$ Treating pollution is a fixed cost, it does not modify marginal production costs. This assumption is realistic and common in the literature (for example in Katsoulacos and Xepapadeas (1995)).
} 


\section{$2.1 \quad$ First-best}

As a benchmark, let us present the first-best values for $x$ and $w$. First-order conditions for the maximization of social welfare give the optimal values $x^{*}$ and $w^{*}$ such as $^{9}$ :

$$
\begin{aligned}
& P\left(n x^{*}\right)=C_{1}^{\prime}\left(x^{*}\right)+v e_{1}^{\prime}\left(x^{*}\right) \\
& C_{2}^{\prime}\left(w^{*}\right)=-v e_{2}^{\prime}\left(w^{*}\right)
\end{aligned}
$$

The first-best price equals marginal cost of production plus marginal social damage associated with production (equation (1)). At the optimal level of abatement effort $w^{*}$, marginal cost of abatement effort equals marginal social benefit from abatement effort (equation (2)).

\subsection{Ex ante equilibrium}

Before any environmental policy, symmetric Cournot-Nash equilibrium is denoted as $\left(x^{c}, w^{c}\right)$. Each firm chooses its output and abatement effort so as to maximize its profit given the other firms' actions.

$$
\max _{x, w} \pi=P(X) x-C(x, w)
$$

which yields ${ }^{10}$ :

$$
\begin{aligned}
P\left(n x^{c}\right) & =C_{1}^{\prime}\left(x^{c}\right)-P^{\prime}\left(n x^{c}\right) x^{c} \\
w^{c} & =0
\end{aligned}
$$

Without policy implementation, firms do not abate pollution. Furthermore, whenever $-P^{\prime}(n x) x \neq v e_{1}^{\prime}(x)$, the output $x^{c}$ chosen by the firms is not the first-best output $x^{*}$ (compare (1) and (3)). This is due to two distorsions: pollution, which implies excessive output, and imperfect competition which leads to insufficient output. If the pollution distorsion dominates, $\left(v e_{1}^{\prime}(x) \geq-P^{\prime}(n x) x\right)$, then $x^{c}$ is superior to $x^{*}$.

Let us assume that the regulator cannot restore a competitive framework and cannot, despite complete information, command firms to produce the optimal level $x^{*}$. Let us study, in this context, an emission tax.

\section{The Emission Tax}

Let the regulator introduce a tax $t$ per unit of emission.

\footnotetext{
${ }^{9}$ Second-order conditions are satisfied.

${ }^{10}$ Second-order conditions are satisfied.
} 


\subsection{Firms' behaviour under the tax}

Each firm now maximizes its profit taking into account the tax payment:

$$
\max _{x, w} \pi^{t}=P(X) x-C(x, w)-t e(x, w)
$$

and values for output and abatement effort now are:

$$
\begin{aligned}
P\left(n x^{t}\right) & =C_{1}^{\prime}\left(x^{t}\right)-P^{\prime}\left(n x^{t}\right) x^{t}+t e_{1}^{\prime}\left(x^{t}\right) \\
C_{2}^{\prime}\left(w^{t}\right) & =-t e_{2}^{\prime}\left(w^{t}\right)
\end{aligned}
$$

The equilibrium price with the tax is higher than at the ex ante equilibrium (compare (3) and (4)), i.e. firms' output is lower $\left(x^{t}<x^{c}\right)$. Furthermore, firms now abate pollution. Their abatement effort equalizes marginal cost of abatement effort and the marginal benefit they derive from abating by thus reducing tax payment (equation (5)).

\subsection{The optimal tax}

In a competitive framework in which pollution is the only distorsion, a Pigovian tax set at marginal social damage of pollution would lead to the firstbest. In an oligopoly, the initial level of production is sub-optimal and a Pigovian tax leads to excessive output contraction. The tax rate must then be lower than the Pigovian rate in order to take into account the distorsion due to imperfect competition ${ }^{11}$. In a model where pollution is proportional to production and the proportionality is fixed, firms' only way to reduce pollution is to reduce their output ${ }^{12}$. A tax on pollution is then equivalent to a tax on production. In this context, the second-best tax rate is equivalent to the combination of a Pigovian emission tax and a subsidy on production, which corrects both distorsions and leads to the first best.

However, we assume here that the proportionality between pollution and production is not fixed as pollution may be abated once it is produced. Firms now take two decisions: output and abatement effort. In reaction to an emission tax, firms choose to reduce pollution in order to reduce their tax payment. They then both reduce production and invest in the abatement technology. However, their private choice between these two means of reducing pollution is not socially optimal. To achieve a given level of pollution, they choose to reduce output excessively and do not invest enough in the

\footnotetext{
${ }^{11}$ Barnett(1980).

${ }^{12}$ Baumol et Oates (1988), Buchanan (1969).
} 
abatement technology. Intuitively, this can be understood by the fact that, by reducing output, firms indirectly obtain a private gain by raising the price, which is not the case when they abate through pollution treatment. Firms excessively transfer the environmental policy's cost on consumers compared to what is socially optimal.

More precisely, in our model, a Pigovian tax, set at marginal social damage $(v)$ would lead to the optimal abatement effort $w^{*}$ (see equations (2) and (5)). However, equations (1) and (4) show that, due to imperfect competition, such a tax would lead to excessive output contraction $\left(x^{v}<x^{*}\right)$ and to too high a price rise. Following the same reasoning, a tax rate $\tilde{t}$ that would lead to the optimal output $x^{*}$, would lead to insufficient abatement effort $\left(w^{\tilde{t}}<w^{*}\right)$.

The second-best tax rate then results from a trade-off between encouraging firms to abate pollution and not inducing to high an output contraction. The formula for this second-best rate, denoted as $t^{* *}$, is given in equation (9) in the appendix. This rate can be split into marginal damage $v$ and a negative term which accounts for the market imperfection. $t^{* *}$ is therefore inferior to the Pigovian rate and we have: $\tilde{t}<t^{* *}<v$. The second-best tax rate $t^{* *}$ will then lead to lower abatement effort than the first-best value $\left(w^{t^{* *}}<w^{*}\right)$ and insufficient output $\left(x^{t^{* *}}<x^{*}\right)$. The emission tax does not lead to the first-best anymore.

We limit our study to the case when the rate $t^{* *}$ is positive. Formally, the second-best rate can be negative if the social damage associated to pollution is very small compared to the distorsion due to the market structure. The environmental problem is then insignificant and the regulator must encourage firms to produce more. If an emission tax is the only available tool, the regulator must set a negative tax (i.e. a subsidy on pollution) to induce firms to produce more. However, an "emission subsidy" is neither realistic nor adapted to such a context, in which regulation is a matter of antitrust policy rather than environmental policy. This case goes beyond the scope of our study. There is a threshold value on marginal social damage due to pollution $(v)$ for $t^{* *}$ to be positive, which is given in the appendix (condition $(10))$.

We have seen that the emission tax does not lead to firms' optimal choice anymore. The issue of environmental policy choice then becomes relevant. Let us compare this tax with another second-best instrument based only on abatement effort. 


\section{The Voluntary Agreement}

The VA is modeled here as a contract on abatement effort $(w)$ and is implemented in combination with the tax. The regulator offers a policy menu to firms by letting them choose between the tax or entering the VA. The VA can be described as a two-step game. In the first step, the regulator offers a contract $\left(w^{V A}\right)$ to the firms and announces the level $\hat{t}$ of the tax. In the second step, firms that choose to sign the VA make abatement effort $w^{V A}$, the others pay the $\operatorname{tax} \hat{t}$.

A firm that signed the VA and does not respect the requirements will have to pay the tax retroactively, which is equivalent to the case where it would have directly chosen to pay the tax. Let us determine the equilibrium with this form of VA before comparing it with the traditional tax.

\subsection{Firms' behaviour and participation constraint}

Firms signing the VA choose output $x^{V A}$ by maximizing their profit, given the VA requirement. Firms' profit with the VA is:

$$
\pi^{V A}=P(X) x^{V A}-C\left(x^{V A}, w^{V A}\right)
$$

We will assume that each firm can sign the VA if and only if all firms choose to do so. This assumption does not modify at all the results of the model and only simplifies the participation constraint. Moreover, it is quite realistic as many VAs are signed with a group of firms represented by an industrial association.

Each firm's output decision when signing the VA is then given by:

$$
P\left(n x^{V A}\right)=C_{1}^{\prime}\left(x^{V A}\right)-P^{\prime}\left(n x^{V A}\right) x^{V A}
$$

As equations (6) and (3) are equivalent, we have:

$$
x^{V A}=x^{c}
$$

Firms' output are the same under the VA and without environmental policies. This form of VA only affects $w$ and has no effect on firms' output and therefore neither on consumers' surplus. This result remains valid for any level of $w^{V A}$. Note that this follows from the assumption of an additively separable cost function. Without additive separability, the VA would affect output but the output contraction would still be inferior than with the tax. Indeed with the VA, firms avoid the tax payment, which reduces their marginal production cost compared to the tax and therefore implies higher output. 
Each firm is free to choose between the VA and the tax $\hat{t}$ and enters the VA if and only if it leads to a higher profit than the tax. We assume that, when both profits are equal, firms choose to enter the VA. The firms' participation constraint to the VA then is:

$$
P\left(n x^{c}\right) x^{c}-C\left(x^{c}, w^{V A}\right) \geq P\left(n x^{\hat{t}}\right) x^{\hat{t}}-C\left(x^{\hat{t}}, w^{\hat{t}}\right)-\hat{t} e\left(x^{\hat{t}}, w^{\hat{t}}\right)
$$

By signing the VA, each firm avoids the tax payment and for a given level of $x$ and $w$, makes a higher profit than with the tax. Moreover, as we have just seen, firms signing the VA produce at the same level $x^{c}$ as without environmental policy which, for a given level of abatement, gives them a higher profit than with the tax. There therefore exists a set of abatement $w^{V A}$, superior to $w^{\hat{t}}$, for which firms will accept the VA. The regulator may still satisfy the participation constraint by offering a contract that leads to a higher abatement than the tax $\hat{t}$.

Let us denote $w^{\max }(\hat{t})$ the maximum level of $w^{V A}$ for which, with a threat $\hat{t}$, the participation constraint is satisfied. Then $w^{\max }(\hat{t})$ is superior to $w^{\hat{t}}$ for all positive values for $\hat{t}^{13}$. Note here the necessity of the threat of the tax. Without this threat, i.e. if $\hat{t}=0$, the only contract that satisfies the participation constraint is $w^{V A}=0$, which is equivalent to the absence of policy.

\subsection{The regulator's choice}

The regulator chooses contract $w^{V A *}$ that maximizes social welfare taking into account firms' participation constraint, and decides on the level $\hat{t}$ of the threat. Ignoring the constraint, the optimal contract is $\left(w^{*}\right)^{14}$. However, the VA will be implemented if and only if the participation constraint is satisfied, which depends on the threat $\hat{t}$.

The level $\hat{t}$ depends on the credibility of the threat. The regulator cannot announce any threat $\hat{t}$ and still be credible. If the VA fails, the regulator will apply the tax at its optimal level $t^{* *}$. Then if firms detain all necessary information to compute $t^{* *}$, the only credible threat is $\hat{t}=t^{* *}$. However, firms may lack information, such as marginal social damage of pollution $v$. The regulator can then announce a $\hat{t}$ superior to $t^{* *}$. In the extreme case where any threat is credible, the regulator will choose any $\hat{t}$ high enough to let the participation constraint be satisfied with contract $\left(w^{*}\right)^{15}$. In order to

\footnotetext{
${ }^{13}$ This result is demonstrated in the appendix.

${ }^{14}$ This result is due to an additively separable cost function and is demonstrated in the appendix.

${ }^{15} w^{\max }(\hat{t})$ is increasing in $\hat{t}$.
} 
keep the discussion on the credibility of the threat open, let us distinguish two cases:

- If, given the level of the credible threat $\hat{t}, w^{*} \leq w^{\max }(\hat{t})$, then the participation constraint is satisfied for the optimal contract $\left(w^{*}\right)$, and the VA reaches the optimal abatement effort. $w^{V A *}=w^{*}$.

- If $w^{*}>w^{\max }(\hat{t})$, the regulator will choose a contract as close as possible to $w^{*}$ but that verifies the constraint, that is $w^{V A *}=w^{\max }(\hat{t})$. In this second case, the VA will reach a sub-optimal level of abatement effort, but still superior to the level obtained with the threat $\hat{t}$ and therefore with the $\operatorname{tax} t^{* * 16}$.

Proposition 1. The voluntary agreement studied here does not affect firms' output and always implies a higher abatement effort from the firms than the optimal emission tax.

\section{Comparison of the Tax and the Voluntary Agreement}

Assuming both policies may be applied at their second-best level $t^{* *}$ and $w^{V A *}$, let us study the conditions under which the VA is more efficient than the tax.

\subsection{An ambiguous comparison}

Considering an industry with two distorsions, one due to pollution and the other to imperfect competition, an emission tax applied at a second-best rate leads to insufficient abatement and insufficient output. In the same context, we have studied a form of VA that does not affect firms' output and reaches a higher abatement than the tax.

In terms of distance to the first-best values, the VA always leads to an abatement effort which is closer to the first-best level than the tax. However, the output level obtained with the VA may be closer or further from first-best output than the output obtained with the tax. This depends on initial output $x^{c}$ compared to optimal output $x^{*}$. Comparison of social welfare under the tax and the VA may therefore be ambiguous.

In the following graph in the $(x, w)$ plan, each curve is associated to a level of social welfare. At values $x^{*}$ and $w^{*}$, we are located at point $\mathrm{S}$ which

\footnotetext{
${ }^{16}$ The regulator will always announce a threat such as: $\hat{t} \geq t^{* *}$. $w^{t}$ is increasing in $t$. We demonstrated that for all $t, w^{\max }(t)>w^{t}$. We therefore have: $w^{\max }(\hat{t})>w^{\hat{t}} \geq w^{t^{* *}}$.
} 
represents first-best situation, i.e. maximal social welfare. The further is a curve from point $\mathrm{S}$, the lower the associated level of welfare.

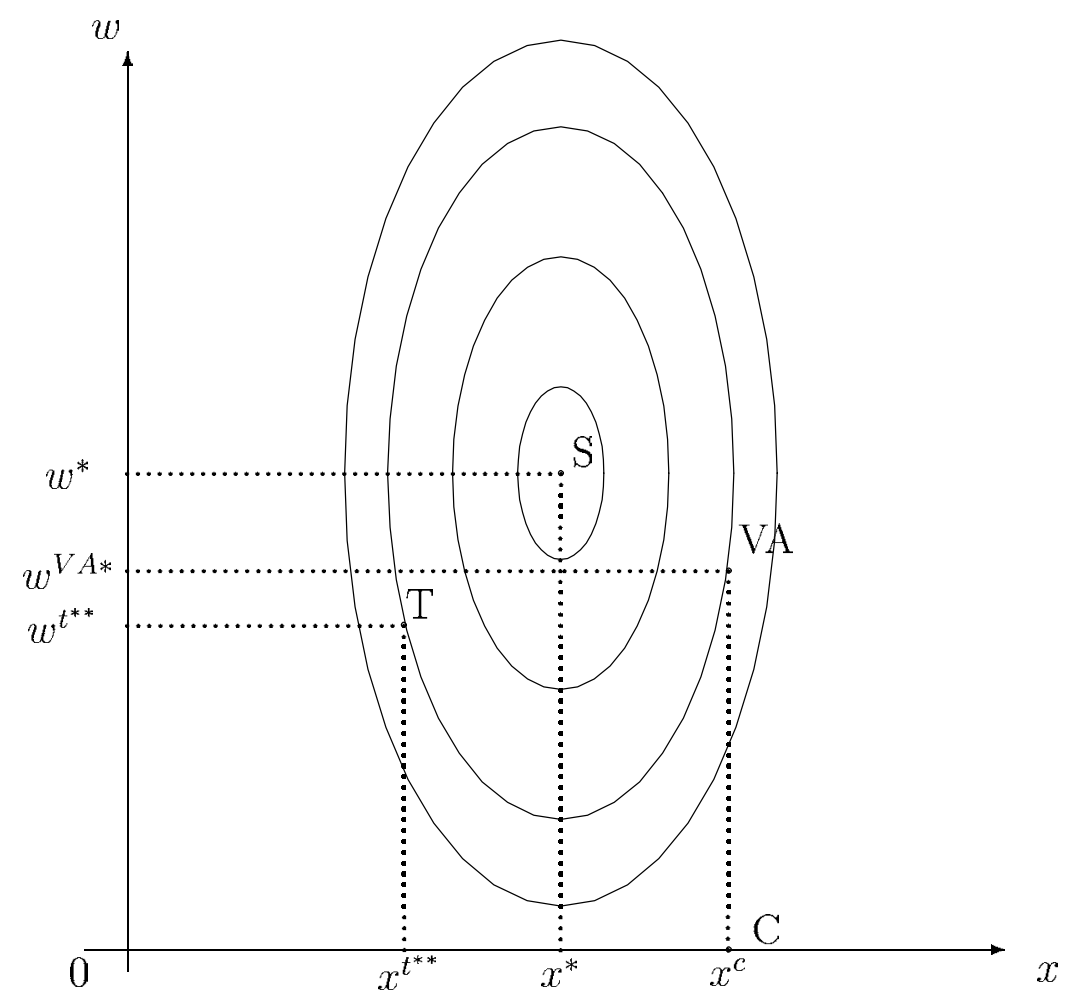

At the ex ante equilibrium, output produced by each firm is $x^{c}$ and abatement effort is zero (point C). With the second-best emission tax, output $x^{t^{* *}}$ is inferior to $x^{c}$ and inferior to $x^{*}$. Abatement effort $w^{t^{* *}}$ is positive but inferior to first-best value $w^{*}$. Point $\mathrm{T}$, which represents the situation with the emission tax, is closer to point $\mathrm{S}$ than before any policy (point $\mathrm{C}$ ). With the VA, output stays at level $x^{c}$ and abatement effort $w^{V A *}$ is between values $w^{t^{* *}}$ and $w^{*}$ (point VA). Point VA is also closer to first-best (point S) than point $\mathrm{C}$. The question is whether the curve on which point $\mathrm{T}$ is located is closer or further from first-best (point $S$ ) than the curve on which point $\mathrm{VA}$ is located. If points $\mathrm{T}$ and VA are on the same curve, both policies are equivalent in terms of social welfare.

The above graph represents the case where initial output $x^{c}$ is superior to $x^{*}$. In the illustrated case, points T and VA are on the same curve. The emission tax and VA lead to the same level of social welfare.

In the case where $x^{c}$ is lower than first-best output $x^{*}$, i.e. the distorsion due to imperfect competition dominates the distorsion due to pollution in 
the value of $x^{c}$, the VA is always more efficient than the tax. This case is illustrated in the following figure:

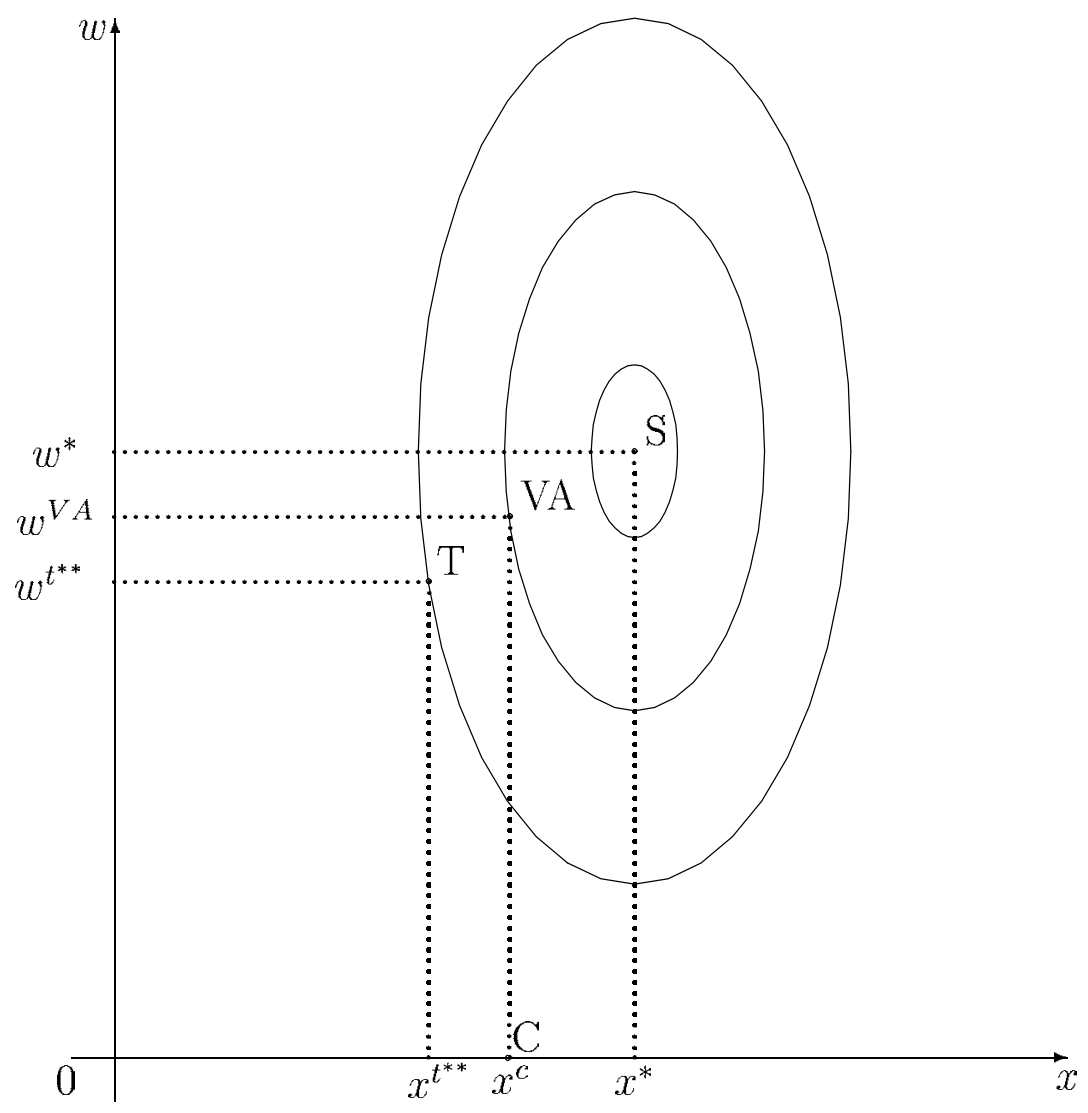

In the case illustrated above, any positive tax leads to output contraction and therefore to an output level $x^{t^{* *}}$ further from $x^{*}$ than $x^{c}$, which was already inferior to $x^{*}$. The VA avoids this undesirable output contraction and allows a higher abatement than the tax. Therefore, whenever $x^{c}<x^{*}$, i.e. whenever the distorsion due to market imperfection is strong; point VA is closer from $\mathrm{S}$ than point $\mathrm{T}$. The VA is then more efficient than the tax.

The form of the represented curves depends on the elasticities of social welfare with respect to $x$ and $w$ which in turn depends on the inverse demand function, the cost function and the emission function. In the next sub-section, we specify the functions of the model in order to allow further comparison between the VA and the emission tax.

Note that beyond the comparison of welfare, the tax and the VA have different effects on agents' surplus. As output is higher with the VA, consumers' surplus is always higher with the $\mathrm{VA}^{17}$. Concerning the firms, there

\footnotetext{
${ }^{17}$ In this model, as it is standard in microeconomics, consumers' surplus only depends
} 
are some cases when the VA lets them have a higher profit than the tax, but this depends on the level of the threat $\hat{t}$. If the threat of the tax is set at level $\hat{t}=t^{* *}$, then, given the participation constraint, the variation of firms' profit between the tax $t^{* *}$ and the VA is positive. But if the credible threat $\hat{t}$ is high, firms' profit may be lower with the VA.

Regarding the effect on pollution of both policies, we cannot say whether the VA leads to higher or lower emissions than the emission tax. The higher pollution abatement associated with the VA rather leads to less emissions than the tax. However, the higher output chosen by firms with the VA plays in favor of higher emissions. The relative effect on emissions of the VA and the tax depends on emissions elasticity with respect to output and abatement.

Note that, in addition to the effects on agents' surplus and on emissions, the VA, in opposition to the tax, does not raise revenues, which implies a loss in social welfare ${ }^{18}$.

\subsection{A formal comparison}

We now specify the functions of the model as follows ${ }^{19}$ :

$$
\begin{aligned}
& C(x, w)=c x+g w ;(0<c<1 ; g>0) \\
& e(x, w)=k x-\sqrt{L w} ;(k>0 ; L>0) \\
& P(X)=1-X
\end{aligned}
$$

Considering the case when the threat $\hat{t}$ is high enough for firms to accept contract $\left(w^{*}\right)$, we derive a necessary and sufficient condition on the parameters for welfare to be higher with the VA than with the emission tax set at the second-best optimal rate ${ }^{20}$ :

$$
L(n+1)^{2} v[2(1-c)-(n+2) k v]>2 k g[(n+1) k v-(1-c)]^{2}
$$

As the second term in equation (7) is always positive, the above inequality may only be satisfied if the first term of this equation is positive, that is if:

$$
v<\frac{2(1-c)}{(n+2) k}
$$

on the price, i.e. on the level of total output.

${ }^{18}$ Tax revenues are redistributed in a neutral way in the economy.

${ }^{19}$ Katsoulacos and Xepapadeas (1995).

${ }^{20}$ This result is demonstrated in the appendix. 
If $v$, marginal social damage associated to pollution, is superior to the threshold given in (8), then the emission tax is always more efficient than the VA.

Proposition 2. For a very harmful form of pollution, the emission tax is always more efficient than the voluntary agreement.

This result can be easily interpreted. The advantage of the VA over the tax lies in the existence of a double distorsion. If $v$ is very high, the distorsion due to market structure becomes insignificant compared to the distorsion due to pollution. The VA then looses its advantage over the tax.

Note that the condition (8) is more easily satisfied for:

- low values for $n$, that is for an industry composed of a small number of firms;

- low values for $k$, that is for a low-polluting industry ${ }^{21}$;

Within an oligopoly composed of many firms (high $n$ ), i.e. close from a perfectly competitive industry, the misallocation resulting from the market structure is insignificant. The negative effect of the tax is therefore limited and the VA's advantage compared to the tax is reduced.

Furthermore, the VA studied here leads to pollution reduction through end-of-pipe abatement only. For a very polluting industry, i.e. for a high $k$, the VA, which does not affect output, does not allow a significant pollution reduction. It is therefore understandable that the VA may be more efficient than the tax only for low polluting industries.

Assuming that the condition (8) is satisfied, let us look into the interpretation of the necessary and sufficient condition (7). This condition can be written as follows:

$$
\frac{L}{g}>\frac{2 k[(n+1) k v-(1-c)]^{2}}{(n+1)^{2} v[2(1-c)-(n+2) k v]}
$$

For high values for $L$, abatement effort $w$ leads to a significant emission reduction. Abatement through pollution treatment is then a relatively efficient way to reduce pollution. Variable $g$ represents marginal cost of abatement effort. Ratio $L / g$ then represents the efficiency of abatement effort divided by its cost. The above condition gives a minimal threshold on $L / g$ for the VA to be more efficient than the tax.

\footnotetext{
${ }^{21} k$ represents the quantity of emissions generated by each unit produced.
} 
Proposition 3. When pollution is not too harmful, the voluntary agreement is more efficient than the emission tax when the abatement technology is rather cheap and efficient.

This result is understandable. For high values for $L / g$, it is socially optimal to reduce pollution mainly through abatement. The tax, which leads to insufficient abatement, is therefore further from first-best than when abatement is inefficient. The VA then has a stronger advantage over the tax.

\subsubsection{Illustration of the necessary and sufficient condition}

Normalizing variable $k$ to $1^{22}$, the necessary and sufficient condition (7) may be represented in the plan $(v, L / g)$ as follows:

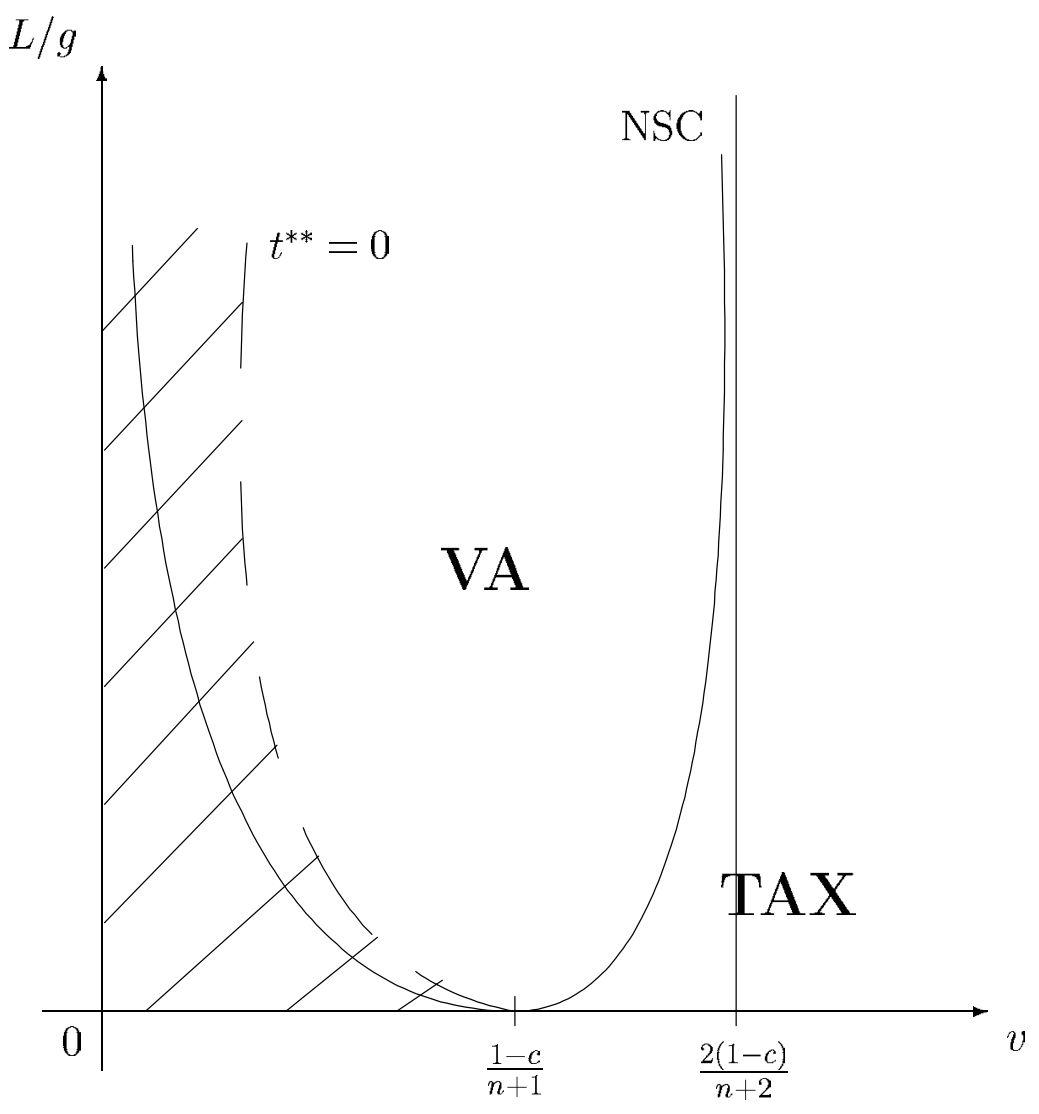

In this figure, the asymptote given by the equation $v=\frac{2(1-c)}{n+2}$ represents the necessary condition (8). On the right-hand side of this asymptote (for high values for $v$ ), condition (8) is not verified and the emission tax is always

${ }^{22}$ Each unity of output generates one unity of emissions. 
more efficient than the VA. On the left-hand side of the asymptote, the parabola denoted as NSC, given by the equation $L / g=\frac{2[v(n+1)-(1-c)]^{2}}{v[2(1-c)-(n+2) v]} \cdot \frac{1}{(n+1)^{2}}$, represents the necessary and sufficient condition (7). Above this parabola, condition (7) is verified and the VA is more efficient than the tax.

The hatched area corresponds to the case, excluded from our study, where $t^{* *}$ is negative because $v$ is small. The equation of the dotted curve, according to condition (12) given in the appendix, is $L / g=\frac{2}{n+1}\left[\frac{1-c}{v(n+1)}-1\right]$.

When $n$, the number of firms in the industry, becomes smaller, the asymptote, the parabola and the dotted curve move towards the right and the area in which the VA is more efficient than the tax becomes larger.

\section{Discussion}

In our model, variable $w$ represents an investment in an abatement technology, which is a specific (even though common) type of clean technology. An additively separable cost function between $w$ and output $x$ is then realistic: end-of-pipe abatement does not modify production costs. However, in other cases, as in the Danish VA, the adoption of a clean technology implies an alteration of the production process. The assumption of additively separable costs is then not valid anymore. We find that the results of the model are qualitatively robust to this assumption. The VA still has a limited effect on output compared to the tax and still reaches higher abatement than the tax with a general form for the cost function. The formal necessary and sufficient condition is modified but all other results hold. The model may therefore be qualitatively generalized to other forms of investment in a clean technology.

Another important point to discuss is the distinction between the content and the form of the VA. The comparison between the VA and the tax mainly rests on the fact that the tax is based on emissions whereas the VA is based on abatement effort. A policy on emissions lets the polluting firms choose between reducing output or abating to obtain a given level of emissions. It therefore leaves the possibility for strategic behaviors from the firms who reduce output excessively. A policy based on abatement effort does not leave such freedom to the firms and therefore has a limited effect on output.

Therefore, the content of the contract $(w)$, rather than the form of the VA as a take-it-or-leave-it contract seems to be the crucial point in the comparison. A mandatory policy imposing a level of abatement effort on the firms rather than letting them choose with the tax would, from a normative point of view, lead to similar results as the VA. More precisely, such a mandatory policy would always be equivalent or more efficient than the VA modeled above. Indeed, assuming complete information, a regulatory standard on $w$ 
would always reach the optimal level $w^{*}$ whereas, depending on the level of the threat $\hat{t}$, the VA may reach a sub-optimal abatement effort: $w^{V A *} \leq w^{*}$.

We can therefore conclude form our results that, when information is available $^{23}$, a mandatory policy may be more efficient than an economic instrument (here a tax) to regulate an oligopoly. The comparison between regulatory standards and economic instruments is modified due to firms' strategic behaviors with imperfect competition. Similar results have been found concerning tradable pollution permits which may also lead to strategic behaviors from the firms and which can therefore may be less efficient than a regulatory standard ${ }^{24}$.

However, from a positive point of view, mandatory standards based on abatement effort do not exist. Regulatory standards take the form of emission quotas or process standards, which impose a specific technology. They never impose a level of effort to adopt a clean technology. The Danish VA studied in this paper seems to be the existing environmental policy that resembles the most such a standard.

One issue therefore remains: what justifies the observation of the "voluntary" form of this policy whereas a mandatory policy would be more efficient? Mandatory policies are often criticized for their lack of acceptability. The take-it-or-leave-it form of the VA may partly solve this problem. However, information may be a more convincing explanation for this form. Up to now, we have assumed the regulator was perfectly informed. The comparison between a policy based on emissions or abatement effort in a imperfect competition framework was quite independent from any informational problems, which justifies our assumption. However, in the comparison of a mandatory or voluntary policy on abatement effort, the informational context may be significant and explain the VA. Further research on this field would be welcome.

The above findings show how much the boundary between VAs and existing instruments is fuzzy and how the issue of the definition of VAs is still problematic. In our model, the VA is in fact an hybrid instrument, combination of a regulatory standard and a tax as a threat. As this example shows it, VAs often seem to be a new way of implementing existing tools rather than a new environmental instrument strictly speaking.

Finally, some of the results of this paper can be compared to the existing literature. According to Brau and Carraro (1999), the use of VAs can be justified in the presence of market failure and imperfect competition. This

\footnotetext{
${ }^{23}$ For example, in the paper industry, pollution treatment technologies are well-known and the assumption of complete information is realistic.

${ }^{24}$ Godard(01), Mc Fetridge and Sartzetakis (1999).
} 
statement corresponds to the framework of our model. The same authors show that "the effectiveness of VAs increases when industry is more concentrated". It is interesting to note that this agrees with one of our results, even though it follows from an other reasoning. Furthermore, Carraro and Siniscalco (1994) highlight the importance of implementing policies specifically designed to promote technological change. They conclude that "the optimal policy to control pollution is a mix of complementary measures which does not necessarily correspond to the conventional environmental policy recommendations", which is exactly the case of the VA we focused on.

\section{Conclusion}

This paper studies environmental policy choice in an imperfect competition framework. There are two ways of reducing pollution: output contraction and end-of-pipe abatement. In this context, the second-best emission tax leads to insufficient output and insufficient abatement.

On the other hand, we study a form of voluntary agreement which induces pollution reduction only through abatement. This VA is a take-it-or-leave-it contract offered to the firms with the threat of the emission tax. The studied VA has no impact on output and always leads to higher abatement than the tax.

Given the framework and assumptions of the model, we derive a necessary and sufficient condition on the parameters of the model for which the VA is more efficient than the optimal emission tax. According to this condition, the emission tax is always more efficient to regulate a very harmful type of pollution and/or in a low-concentrated and/or very polluting industry. Otherwise, the VA may be more efficient than the emission tax when the abatement technology is rather efficient and cheap.

Beyond the comparison of social welfare, the VA and the emission tax have different distributive impacts, which may constitute a significant criterion in the environmental policy choice. From the consumers' point of view, the VA is always preferred to the tax, since it avoids output contraction. From the firms' point of view, there are cases when the VA is preferred to the second-best tax but it depends on the level of the threat of the tax.

Note finally that there exists other forms of environmental policies which, as the VA studied here, have a limited impact on output. It is the case for a form of tax implemented in Sweden, where the revenues of the tax are distributed to the firms according to their output. It is also the case for permit markets in which the initial allocation of permits is proportional to firms' output. It would be interesting to include these instruments in the 
comparison of environmental policies within imperfect competition.

\section{References}

Barnett, A. H., 1980, "The Pigouvian tax rule under monopoly", American Economic Review, 70: 1037-41.

Baumol, W.J. and Oates, W.E, 1988, "The Theory of Environmental Policy", 2nd edition, Cambridge University Press.

Brau, R. and Carraro, C., 1999, "Voluntary approaches, market structure and competition", FEEM Fondazione Eni Enrico Mattei, Nota di Lavoro.

Buchanan, J. M., 1969, "External Diseconomies, Corrective Taxes and Market Structure", American Economic Review, 59: 174-177.

Carraro, C. and Siniscalco, D., 1994, "Environmental Policy Reconsidered: the Role of Technological Innovation", European Economic Review, 38: $545-554$.

Conrad, K. and Wang, J., 1993, "The Effect of Emission Taxes and Abatement Subsidies on Market Structure", International Journal of Industrial Organization, 11.

Cropper, M. L. and Oates, W. E., 1992, "Environmental Economics: A Survey". Journal of Economic Literature, 30: 75-740.

Godard, O., 2001, "Permis Transférables Nationaux et Politiques Environnementales: Conception et Application", OCDE.

Johannsen, K. and Togeby, M., 1998, "Evaluation of the Danish CO2 Agreement Scheme", paper presented at the CAVA (Concerted Action on Voluntary Approach) workshop "The world-wide use of voluntary approachesState of the Art and National Patterns", Gent, Belgium.

Katsoulacos, Y. and Xepapadeas, A., 1995, "Environmental Policy under Oligopoly with Endogenous Market Structure", Scandinavian Journal of Economics, 97(3): 411-420. 
Mc Fetridge, D. G. and Sartzetakis, E. S., 1999, "Emissions Permits Trading and Market Structure", in Environmental Regulation and Market Power, E. Patrakis, E. S. Sartzetakis et A. Xepapadeas, Edward Elgar Publishing.

OECD, 1999, "Voluntary Approaches for Environmental Policies: an Assessment".

\section{Appendix}

Formula for $t^{* *}$ and condition on $v$ for $t^{* *}$ to be positive:

Maximization of social welfare with an emission tax yields the following second-best tax rate inferior to $v^{25}$ :

$$
t^{* *}=\frac{P^{\prime}\left(n x^{t}\right) \cdot x^{t} \cdot \frac{d x^{t}}{d t}}{e_{1}^{\prime}(x) \cdot \frac{d x^{t}}{d t}+e_{2}^{\prime}(w) \cdot \frac{d w^{t}}{d t}}+v
$$

We exclude from our analysis the case when the second-best rate is negative, which can happen when $v$ is small. We therefore assume that marginal social damage of pollution is superior to the following (positive) threshold:

$$
v \geq-\frac{P^{\prime}\left(n x^{t}\right) \cdot x^{t} \cdot \frac{d x^{t}}{d t}}{e_{1}^{\prime}(x) \cdot \frac{d x^{t}}{d t}+e_{2}^{\prime}(w) \cdot \frac{d w^{t}}{d t}}
$$

Proof of $w^{\max }(\hat{t})$ superior to $w^{\hat{t}}$ for all $\hat{t}$ :

$w^{\max }(\hat{t})$ is the maximum level of $w^{V A}$ for which the participation constraint is satisfied, with threat $\hat{t}$ :

$$
P\left(n x^{c}\right) x^{c}-C\left(x^{c}, w^{\max }(\hat{t})\right)=P\left(n x^{\hat{t}}\right) x^{\hat{t}}-C\left(x^{\hat{t}}, w^{\hat{t}}\right)-\hat{t} e\left(x^{\hat{t}}, w^{\hat{t}}\right)
$$

The cost function being additively separable, this can be written as:

$P\left(n x^{c}\right) x^{c}-C\left(x^{c}, w^{\hat{t}}\right)-C\left(0, w^{\max }(\hat{t})\right)+C\left(0, w^{\hat{t}}\right)=P\left(n x^{\hat{t}}\right) x^{\hat{t}}-C\left(x^{\hat{t}}, w^{\hat{t}}\right)-\hat{t} e\left(x^{\hat{t}}, w^{\hat{t}}\right)$

Then:

$C\left(0, w^{\max }(\hat{t})\right)-C\left(0, w^{\hat{t}}\right)=P\left(n x^{c}\right) x^{c}-C\left(x^{c}, w^{\hat{t}}\right)-\left[P\left(n x^{\hat{t}}\right) x^{\hat{t}}-C\left(x^{\hat{t}}, w^{\hat{t}}\right)\right]+\hat{t} e\left(x^{\hat{t}}, w^{\hat{t}}\right)$

${ }^{25}$ This result agrees with Barnett (1980)'s formula. 
The above expression is positive because:

$$
\hat{t} e\left(x^{\hat{t}}, w^{\hat{t}}\right) \geq 0, \forall \hat{t}>0
$$

and:

$$
P\left(n x^{c}\right) x^{c}-C\left(x^{c}, w^{\hat{t}}\right)-\left[P\left(n x^{\hat{t}}\right) x^{\hat{t}}-C\left(x^{\hat{t}}, w^{\hat{t}}\right)\right]>0, \forall \hat{t}
$$

as $x^{c}$ is the Cournot-Nash value for firms' output.

Therefore:

$$
C\left(0, w^{\max }(\hat{t})\right)-C\left(0, w^{\hat{t}}\right)>0, \forall \hat{t}>0
$$

And, given the assumptions on $C$ :

$$
w^{\max }(\hat{t})>w^{\hat{t}}, \forall \hat{t}>0 \quad Q E D
$$

Proof of the optimal level of abatement effort with the VA:

$w^{V A *}$ maximizes social welfare with the $\mathrm{VA}$ :

$$
\max _{w^{V A}} W^{V A}=\int_{0}^{n x^{c}} P(u) d u-n C\left(x^{c}, w^{V A}\right)-v n e\left(x^{c}, w^{V A}\right)
$$

First-order condition gives $\mathrm{us}^{26}$ :

$$
C_{2}^{\prime}\left(w^{V A *}\right)=-v \epsilon_{2}^{\prime}\left(w^{V A *}\right)
$$

This equation is equivalent to equation (2). Given the assumptions on $C$ and $e$ we have:

$$
w^{V A *}=w^{*} \quad Q E D
$$

Proof of condition ( 7$)$ :

$C(x, w)=c x+g w ;(0<c<1 ; g>0)$

$e(x, w)=k x-\sqrt{L w} ;(k>0 ; L>0)$

$P(X)=1-X$

Values for output and pollution treatment are:

- at first-best:

$x^{*}=\frac{1-c-k v}{n} ; w^{*}=L\left(\frac{v}{2 g}\right)^{2}$

- before any environmental policy:

$x^{c}=\frac{1-c}{n+1} ; w^{c}=0$;

- with the emission tax $t$ :

\footnotetext{
${ }^{26}$ Second-order conditions are satisfied.
} 
$x^{t}=\frac{1-c-k t}{n+1} ; w^{t}=L\left(\frac{t}{2 g}\right)^{2}$

- with the VA:

$x^{V A}=x^{c}=\frac{1-c}{n+1} ; w^{V A}=w^{*}=L\left(\frac{v}{2 g}\right)^{2}$

Conditions on the parameters:

$0<c<1 ; g>0 ; k>0 ; L>0 ; n$ is a non-negative integer superior to 1 Condition on $v$ for $t^{* *}$ to be positive:

The second-best tax rate is:

$$
\begin{aligned}
t^{* *} & =\frac{P^{\prime}\left(n x^{t}\right) \cdot x^{t} \cdot \frac{d x^{t}}{d t}}{e_{1}^{\prime}(x) \cdot \frac{d x^{t}}{d t}+e_{2}^{\prime}(w) \cdot \frac{d w^{t}}{d t}}+v \\
& =\frac{v(n+1)\left[k^{2}+(n+1) \cdot \frac{L}{2 g}\right]-k(1-c)}{k^{2} n+(n+1)^{2} \cdot \frac{L}{2 g}}
\end{aligned}
$$

$t^{* *}$ is then positive if and only if:

$$
v \geq \frac{k(1-c)}{(n+1)\left[k^{2}+(n+1) \frac{L}{2 g}\right]}
$$

Variation of welfare between the tax and the VA:

$$
\Delta W=W^{V A}-W^{t}=\Delta C S+n \Delta \pi-n v \Delta e-n t e\left(x^{t}, w^{t}\right)
$$

where $\Delta C S, \Delta \pi$ et $\Delta e$ respectively denote variation of consumers' surplus, variation of firms' profits and variation of firms' emissions. The last term represents the tax revenues.

$$
\begin{gathered}
\Delta C S=\int_{0}^{n x^{c}} P(u) d u-n x^{c} P\left(n x^{c}\right)-\left[\int_{0}^{n x^{t}} P(u) d u-n x^{t} P\left(n x^{t}\right)\right] \\
=\frac{n^{2}}{2}\left[\frac{2(1-c) k t-(k t)^{2}}{(n+1)^{2}}\right] \\
\Delta \pi=\left(1-n x^{c}\right) x^{c}-c x^{c}-g w^{*}-\left(1-n x^{t}\right) x^{t}+c x^{t}+g w^{t}+t e\left(x^{t}, w^{t}\right) \\
=\frac{(1-c)(1-n) k t+n(k t)^{2}}{(n+1)^{2}}-\frac{L\left(v^{2}-t^{2}\right)}{4 g}+t e\left(x^{t}, w^{t}\right) \\
\Delta e=k x^{c}-\sqrt{L w^{*}}-k x^{t}+\sqrt{L w^{t}} \\
=\frac{k^{2} t}{n+1}-\frac{L(v-t)}{2 g}
\end{gathered}
$$


Which gives:

$$
\begin{gathered}
\Delta W=\frac{n^{2}}{2}\left[\frac{2(1-c) k t-(k t)^{2}}{(n+1)^{2}}\right]+n\left[\frac{(1-c)(1-n) k t+n(k t)^{2}}{(n+1)^{2}}-\frac{L\left(v^{2}-t^{2}\right)}{4 g}\right]-n v\left[\frac{k^{2} t}{n+1}-\frac{L(v-t)}{2 g}\right] \\
\Delta W=n\left[\frac{2(1-c) k t+n(k t)^{2}-2(n+1) k^{2} t v}{2(n+1)^{2}}+\frac{L\left(v^{2}+t^{2}-2 v t\right)}{4 g}\right]
\end{gathered}
$$

Sign of the variation of welfare:

The sign of $\Delta W$ is the same as the sign of the following polynomial, denoted as $Q$ :

$Q=\left\{(n+1)^{2} L+2 n g k^{2}\right\} t^{2}-\left\{2 v(n+1)^{2} L+4 k g[(n+1) k v-(1-c)]\right\} t+(n+1)^{2} L v^{2}$

$Q$ is a second degree polynomial in $t$. $D$ denotes its discriminant. Simplificating $D$ yields:

$$
D=8 g k v(n+1)^{2} L[(n+2) k v-2(1-c)]+\{4 g k[(n+1) k v-(1-c)]\}^{2}
$$

Three cases are considered according to the sign of $D$ :

- If the discriminant is positive $(D>0)$, we obtain two positive roots for $Q$ :

$$
\begin{aligned}
& t 1=\frac{2 v(n+1)^{2} L+4 g k[(n+1) k v-(1-c)]-\sqrt{D}}{2\left[(n+1)^{2} L+2 n g k^{2}\right]} \\
& t 2=\frac{2 v(n+1)^{2} L+4 g k[(n+1) k v-(1-c)]+\sqrt{D}}{2\left[(n+1)^{2} L+2 n g k^{2}\right]}
\end{aligned}
$$

The first coefficient in polynomial $Q$ is always positive so polynomial $Q$ is positive for values for $t$ outside the interval $\left[t_{1}, t_{2}\right]$.

The tax is implemented at its optimal level $t^{* *}$. Let us study whether $t^{* *}$ is inside or outside interval $\left[t_{1}, t_{2}\right]$.

$$
t^{* *}=\frac{v(n+1)\left[k^{2}+(n+1) \cdot \frac{L}{2 g}\right]-k(1-c)}{k^{2} n+(n+1)^{2} \cdot \frac{L}{2 g}}
$$

We find that $t^{* *}$ is always inside interval $\left[t_{1}, t_{2}\right]$. Therefore polynomial $Q$ is always negative in the case where discriminant $D$ is positive.

- If the discriminant is equal to zero $(D=0)$, polynomial $Q$ has a unique root equal to $t^{* *}$. The VA is then equivalent to the optimal emission tax. 
- If the discriminant is negative $(D<0)$, polynomial $Q$ has no roots in $\mathbb{R}^{+}$. The first coefficient in polynomial $Q$ is always positive so $Q$ is always positive. Then welfare is always higher with the VA than with the tax.

The necessary and sufficient condition for the VA to be more efficient than the tax is then that discriminant $D$ be negative, that is:

$$
D=8 g k v(n+1)^{2} L[(n+2) k v-2(1-c)]+\{4 k g[(n+1) k v-(1-c)]\}^{2}<0
$$

which leads to condition (7):

$$
L(n+1)^{2} v[2(1-c)-(n+2) k v]>2 k g[(n+1) k v-(1-c)]^{2} \quad Q E D
$$

